\title{
CARACTERIZAÇÃO DE VARIEDADES DE BATATA DO MUNICIPIO DE CONTENDA-PR E INDICAÇÕES QUANTO AO USO DOMÉSTICO E TECNOLÓGICO
}

\section{CHARACTERIZATION OF POTATO VARIETIES OF THE MUNICIPIO OF STRIFE-PR AND INDICATIONS AS TO THE HOUSEHOLD AND TECHNOLOGICAL}

\footnotetext{
${ }^{1 \bowtie}$ José Luiz Ferreira da Trindade; Ana Mery de Oliveira Camlofski ${ }^{2}$; Renato João Sossela de Freitas ${ }^{2}$

${ }^{1,3}$ Universidade Tecnológica Federal do Paraná - UTFPR - Ponta Grossa: josetrindade@utfpr.edu.br (Autor correspondente)

${ }^{2}$ Programa de Pós-Graduação em Tecnologia de Alimentos, Universidade Federal do Paraná - UFPR
}

\begin{abstract}
Resumo
A batata, Solanum tuberosum L, nativa dos Andes, da região do Peru e Colômbia, já era consumida há 8000 anos. Tubérculo rico em carboidratos, a batata apresenta duas vezes mais proteínas que a mandioca, além de vitaminas e sais minerais. O brasileiro consome aproximadamente $13 \mathrm{~kg} / \mathrm{ano}$, enquanto a média de consumo de europeus e americanos é cinco vezes maior. Estes dados indicam o grande potencial de aumento de consumo de batata no Brasil. O Município de Contenda tem sido um dos maiores produtores de batata no estado do Paraná. O presente trabalho avaliou as variedades Achat, Contenda, Delta, Elvira e Monalisa quanto ao teor de seus principais componentes físico-químicos: umidade, cinzas, sólidos totais, amido, acidez titulável e vitamina C. A classificação comercial foi também realizada. As variedades Delta, Elvira e Monalisa, nesta ordem, apresentaram os melhores índices para sólidos totais, parâmetro de grande importância para a indicação de diferentes variedades quanto ao seu uso doméstico ou tecnológico. O maior teor de sólidos totais foi apresentado pela variedade Delta (20,62\%), vindo a seguir as variedades Elvira e Monalisa (20,10 e 19,69\%) respectivamente. O maior teor de amido foi encontrado na cultivar Elvira, 16,84\%, seguida pela cultivar Delta, com 15,27\%. Em relação aos teores de ácido ascórbico, a cultivar Contenda, obteve o $4,92 \mathrm{mg} 100 \mathrm{~g}^{-1}$. A partir dos resultados obtidos, pode se concluir a importância caracterização físico química das diferentes variedades de batata, para a correta indicação de processamento, quer doméstico ou industrial.

Palavras-chave: Solanum tuberosum; variedades; composição; indicações tecnológicas.
\end{abstract}

\section{Introdução}

A batata (Solanum tuberosum, L) nativa da América do Sul (MARWAHA, 1988) é a 
hortaliça mais plantada no Brasil (FERNANDES et al, 2010), com grande expansão econômica em, vários estados, como São Paulo, Minas Gerais e Paraná. O crescente incremento na produção é uma resposta frente às mudanças de hábito alimentar e à alta demanda de batata para o consumo in natura e processada (POPP, 1994) .

Em âmbito mundial, a batata se destaca como alimento de grande importância, sendo um dos produzidos em maior volume, ficando atrás somente do trigo, do arroz e do milho. Em termos de valor alimentício, destaca-se como fonte de carboidratos, sais minerais e algumas vitaminas. É industrializada e comercializada, regularmente, como batata frita no formato chips, em corte circular, ou batata-palha, na forma de pequenos bastonetes irregulares, sendo consumida como aperitivo e lanches, ou acompanhando refeições (EMBRAPA, 2005).

A batata é uma excelente fonte de carboidratos e contém significativas quantidades de fósforo, potássio, cálcio, vitaminas, especialmente vitamina C (WOOLF, 1991). O seu teor de proteína está acima de $10 \%$ em base seca, relativamente próximo da farinha de trigo com 11\%. Em razão do seu alto valor nutritivo e lisina, metionina e cisteína presentes, torna-se valiosíssima como suplemento de proteínas de cereais (SALUNKHE et al., 1991). Em adição, a batata provê minerais, principalmente o ferro, e vitaminas, como a tiamina, ácido nicotínico, riboflavina e pró-vitamina $\mathrm{A}$ (KADAM e SALUNKHE, 1991; QUADROS, 2005).

O Brasil produziu em 2010, aproximadamente 3,6 milhões de toneladas de batata, com um rendimento de $25 \mathrm{mil} \mathrm{kg/ha} \mathrm{(IBGE,} \mathrm{2012),} \mathrm{sendo} \mathrm{que} \mathrm{sua} \mathrm{comercialização} \mathrm{é} \mathrm{principalmente} \mathrm{na} \mathrm{forma}$ “in natura”, sendo pouco significativa a comercialização para a indústria. Com o crescimento de cerca de $13 \%$ na demanda nos anos 90, devido a adoção de novos padrões alimentares, como a preferência por produtos pré-fritos e congelados, fez-se necessário melhoramento genético para que a batata nacional aumentasse a porcentagem de sólidos solúveis, tornando-se adequada para a indústria (ANDREU, 2003). O Paraná foi o terceiro maior produtor de batata no ano de 2010, com 766.558 toneladas de batata, representando 19,7\% da produção nacional. O estado de Minas Gerais foi o primeiro produtor com $31,0 \%$ e o estado de São Paulo, segundo, com $21 \%$ da produção brasileira naquele ano (IBGE, 2012).

Uma das grandes dificuldades da cultura da batata é a sazonalidade da oferta (produção) ao longo do ano. Isso causa enorme variação nos preços do produto ao consumidor, motivando a necessidade de processamento industrial, mantendo a disponibilidade e preços equilibrados durante a maior parte do ano (SEAB, 1990).

As recomendações para a escolha de uma cultivar de batata para o plantio levam em consideração algumas características, como produtividade, boa resistência a doenças, tubérculos com boa conformação e livres de manchas internas, com boa consevação e alguma resistência ao 
esverdeamento (DIAS, 1986).

A escolha de cultivares de batata no Brasil em função de suas caracacteristicas organolépticas para a culinária ou processamento industrial marca o início da industrialização da batata no Brasil (CARDOSO e SATURNINO, 1993) e vem sendo aprimorada com o aumento do processo agroindustrial. Freitas et al (2006) destacam os parâmetros que influenciam a qualidade de tubérculos para a industrialização, os teores de matéria seca e açúcares redutores.

As principais batatas cultivadas no Paraná e principalmente na região de Contenda (PR) são Elvira, Monalisa, Delta, Contenda e Achat (BUSO, 1989). A avaliação da qualidade de novas variedades ou das já existentes, pode fornecer indicações seguras e essenciais para o consumidor ou para processamento (CHENG et al., 1990).

O processamento de batatas em suas diversas formas é uma realidade na maioria dos países desenvolvidos, já há vários anos, eliminando uma série de inconvenientes, como o armazenamento doméstico, descasque manual, fritura ou cozimento (STRINGHETA, 1989).

As características organolépticas mais importantes para o consumo doméstico ou processamento industrial incluem o sabor, odor, consistência e coloração, visto que despertam atratividade sensorial positiva, sendo indicativos da qualidade da batata. Sabor e aroma dependem da composição físico-química do tubérculo (LESCZCZYNSKI, 1989). A consistência da batata cozida é afetada por vários aspectos como: esfarelamento, maleabilidade, qualidade farinácea, umidade e estrutura da massa da batata. Nonaka e Timm (1983) avaliaram qualidade a textural das batatas, relacionando tempo de cozimento vapor, força de agregação entre células, com iguais e diferentes concentrações de sólidos. Kadam et al (1991) designaram o peso específico como uma das mais significativas influências na qualidade do processamento de batata, extensivamente utilizadas por processadores para avaliar a conveniência na fabricação de fritas a francesa, chips e produtos desidratados.

A necessidade de medir a presença de sacarose e açúcares redutores como indicativo da maturidade, armazenabilidade e processabilidade da batata foi amplamente destacada (GOULD e PLIMPTON, 1987). Pineli et al (2006) e Smith (1975) definiram a matéria seca da batata como sendo constituída de amido, açúcares, substâncias pécticas, celulose, minerais e proteínas. Estes constituintes afetam o processamento industrial, principalmente a absorção de óleo em diferentes taxas e quantidades durante o processo de fritura, bem como produtos como purês reconstituídos, batatas tipos "chips" e na forma de flocos.

O amido é o único componente que separado do tubérculo já é produto final (BOBBIO e BOBBIO, 1989). Marawaha (1988) avaliando a composição química de dez variedades de batata, encontrou valores para o amido entre 12,3 e 18,3\%, sendo o valor médio 15,89\%. 
O objetivo do presente trabalho foi avaliar a composição físico-química de algumas cultivares de batata, mais plantadas no município de Contenda-PR. A partir destes dados, outra meta será apresentar algumas indicações quanto ao uso doméstico e ou de processamento industrial das mesmas.

\section{Material e métodos}

A matéria-prima foi composta por tubérculos de batata (Solanum tuberosum L.), das cultivares Achat, Contenda, Elvira, Monalisa e Delta, escolhidas entre as mais plantadas no município de Contenda-PR, município com maior produção no estado do Paraná. As cultivares se enquadram dentro do grupo "comum", destinadas ao consumo in natura e foram separadas das batatas destinadas à comercialização, imediatamente após a colheita. Foram classificadas e posteriormente lavadas com os procedimentos normais de produto comercial. A amostragem foi realizada de modo aleatório, conforme descrito por Gould e Plimton (1987).

As amostras compreenderam quantidades variáveis de batatas, entre 6,4 e 9,3 kg. O número de tubérculos também apresentou grande variação, sem danos mecânicos e com bom aspecto. Com relação a cultivar Contenda, foram coletadas amostras de duas regiões do município, optando-se pela análise em separado, sendo classificadas como Contenda ${ }_{1}$ Contenda ${ }_{2}$. Em seguida foram acondicionadas separadamente, catalogadas, armazenadas em ambiente fresco e de pouca luminosidade até a execução das análises. A preparação das amostras consistiu em secar ao ambiente e em seguida procedeu-se a avaliação físico-química. Para as análises físicas, no total de tubérculos que compunham as amostras, foram determinados o comprimento, o diâmetro maior e o menor. A massa foi determinada em balança analítica com precisão de $0,1 \mathrm{~g}$. A densidade foi avaliada por imersão dos tubérculos em salmouras com concentrações conhecidas, aferidas por densímetro com as diversas correções de temperatura, considerando a densidade do tubérculo igual à da salmoura onde se estabeleceu o equilíbrio.

As análises físico-químicas foram realizadas em triplicata. A umidade foi determinada por gravimetria a $105{ }^{\circ} \mathrm{C}$ em estufa com circulação de ar até massa constante (BRASIL, 2005), sendo utilizado um tubérculo in natura, processado na forma de "palha", sendo utilizados cinco gramas para a determinação. Os sólidos totais, calculados por diferença da umidade (IAL, 2008).

cinzas foram obtidas por calcinação em mufla a $550{ }^{\circ} \mathrm{C}$, por quatro horas, até massa constante segundo adaptação do método da AOAC (1984). O amido foi estimado pela quantificação dos açúcares não redutores, calculados pela diferença entre carboidratos e açúcares redutores, expressos em percentagem (IAL, 2008). A acidez titulável foi determinada pelo método titulométrico, com 
valor expresso em $\mathrm{mL}$ de $\mathrm{NaOH} \mathrm{N} / 100 \mathrm{~g}$ (IAL, 2008).

A vitamina $\mathrm{C}$ foi determinada pelo método de Tillmans (IAL, 2008).

\section{Resultados e Discussão}

Os parâmetros físicos das cultivares de batata analisadas são apresentados na Tabela1.

Tabela 1- Parâmetros físicos das cultivares de batata Achat, Contenda, Monalisa, Elvira e Delta.

\begin{tabular}{|c|c|c|c|c|c|c|}
\hline Cultivares & $\begin{array}{l}\text { Comprimento } \\
(\mathrm{cm})\end{array}$ & $\begin{array}{l}\mathrm{Ll}^{*} \\
(\mathrm{~cm})\end{array}$ & $\begin{array}{l}\mathrm{L} 2^{*} \\
(\mathrm{~cm})\end{array}$ & $\begin{array}{c}\text { Massa da } \\
\text { amostra } \\
(\mathrm{kg})\end{array}$ & $\begin{array}{l}\text { Massa do } \\
\text { tubérculo } \\
\quad(\mathrm{g})\end{array}$ & $\begin{array}{l}\text { Densidade } \\
\left(\mathrm{g} . \mathrm{cm}^{-3}\right)\end{array}$ \\
\hline Achat & $8,9 \pm 1,2$ & $7,5 \pm 1,4$ & $5,4 \pm 0,9$ & 7,124 & $169,62 \pm 4,6$ & $1,060 \pm 0,004$ \\
\hline Contenda $_{1}$ & $5,4 \pm 1,5$ & $4,3 \pm 1,3$ & $3,8 \pm 1,2$ & 6,123 & $60,03 \pm 4,5$ & $1,064 \pm 0,006$ \\
\hline Contenda $_{2}$ & $7,2 \pm 1,4$ & $6,0 \pm 0,8$ & $5,4 \pm 0,6$ & 7,345 & $128,86 \pm 5,2$ & $1,060 \pm 0,005$ \\
\hline Monalisa & $9,5 \pm 1,4$ & $6,2 \pm 0,6$ & $5,1 \pm 0,6$ & 7,085 & $177,12 \pm 5,3$ & $1,065 \pm 0,004$ \\
\hline Elvira & $7,2 \pm 1,1$ & $5,2 \pm 0,5$ & $4,7 \pm 0,7$ & 9,341 & $97,30 \pm 3,4$ & $1,068 \pm 0,006$ \\
\hline Delta & $6,8 \pm 1,2$ & $6,1 \pm 1,0$ & $6,0 \pm 0,8$ & 2,727 & $118,58 \pm 6,3$ & $1,070 \pm 0,104$ \\
\hline
\end{tabular}

A cultivar Monalisa apresentou em média o maior comprimento, seguida da cultivar Achat. A cultivar Contenda, foi a que obteve as menores medidas. Silva et al (2007) comprovaram que o grande desafio no melhoramento genético da batata é contemplar o desejo dos consumidores, que buscam produtos de qualidade visual e culinária; da indústria, que prioriza qualidade industrial e dos produtores, que almejam rendimento.

Garcia et al (1996) concluiram que existe uma grande variação em relação as dimensões e massa dos tubérculos entre e dentro das variedades e dentro dos tipos mais comercializados. Os formatos igualmente se evidenciam, pelas diferenças entre os diâmetros maior $\left(\mathrm{L}_{1}\right.$ e $\left.\mathrm{L}_{2}\right)$. Conforme Paschoalino et al (1983), cultivares com alto comprimento são indicadas para obtenção de fritas com bom nível de qualidade. Bregagnoli (2006) avaliou que diferenças nos tamanhos, massa e sólidos totais entre os tubérculos estão relacionadas às diferenças entre cultivares e fertilidade das áreas de plantio.

Com relação à densidade, as cultivares não apresentaram grande variação. A cultivar Delta obteve densidade no maior valor de 1,070 g. $\mathrm{cm}^{-3}$, similar ao resultado encontrado por Paschoalino e Fonseca (1987) para a cultivar Bintje, na região de Itatiba-SP, em amostras que obtiveram excelente desempenho industrial tanto em batata tipo fritas, como conservadas em processos de congelamento. Os resultados obtidos evidenciaram uma homogeneidade entre as amostras, resultante das boas condições de manejo da cultura e do grau de adaptação da cultura na região.

A tabela 2 apresenta os resultados para a composição química das cultivares analisadas. 
TABELA 2 - Composição química dos tubérculos de batata das cultivares Achat, Contenda e Contenda $_{2}$, Monalisa Elvira e Delta, cultivadas no Município de Contenda - PR.

\begin{tabular}{|c|c|c|c|c|c|c|}
\hline Cultivares & $\begin{array}{l}\text { Umidade } \\
(\%)\end{array}$ & $\begin{array}{c}\text { Sólidos Totais } \\
(\%)\end{array}$ & $\begin{array}{l}\text { Amido } \\
(\%)\end{array}$ & $\begin{array}{c}\text { Cinzas } \\
(\%)\end{array}$ & $\begin{array}{c}\text { Acidez titulável } \\
\left(\mathrm{mL} \mathrm{NaOH} \mathrm{N} .100 \mathrm{~g}^{-1}\right)\end{array}$ & $\begin{array}{l}\text { Ácido Ascórbico } \\
\left(\mathrm{mg} .100 \mathrm{~g}^{-1}\right)\end{array}$ \\
\hline Achat & $84,46 \pm 0,05^{*}$ & $15,54 \pm 0,10$ & $13,30 \pm 0,07$ & $0,70 \pm 0,04$ & $1,78 \pm 0,09$ & $1,25 \pm 0,06$ \\
\hline Contenda $_{1}$ & $82.35 \pm 0,56$ & $17,65 \pm 0,55$ & $13,87 \pm 0,03$ & $0,62 \pm 0,04$ & $1,54 \pm 0,20$ & $4,92 \pm 0,04$ \\
\hline Contenda $_{2}$ & $82,25 \pm 0,42$ & $17,75 \pm 0,44$ & $15,17 \pm 0,71$ & $0,40 \pm 0,10$ & $2,27 \pm 0,10$ & $4,35 \pm 0,09$ \\
\hline Monalisa & $80,31 \pm 0,05$ & $19,69 \pm 0,29$ & $15,21 \pm 0,55$ & $0,61 \pm 0,05$ & $2,78 \pm 0,70$ & $3,70 \pm 1,20$ \\
\hline Elvira & $79,90 \pm 0,34$ & $20,10 \pm 0,32$ & $16,84 \pm 0,18$ & $0,87 \pm 0,06$ & $2,13 \pm 0,02$ & $2,99 \pm 0,02$ \\
\hline Delta & $79,38 \pm 0,76$ & $20,62 \pm 0,35$ & $15,27 \pm 0,81$ & $0,78 \pm 0,06$ & $1,86 \pm 0,07$ & $3,50 \pm 0,23$ \\
\hline
\end{tabular}

*Valor dos desvios padrões.

A variação encontrada para o teor de umidade, entre $79,38 \%$ para a cultivar Achat e $84,46 \%$, podem ser atribuídas às diferenças genéticas entre elas, safra, adubação e de fertilidade ente as diversas áreas de cultivo e os valores similares aos relatados por Fernandes et al.(2010). No trabalho, referido o autor encontrou valores de matéria seca variando entre 13, 30\% para a cultivar Mondial, até $19 \%$ para a Atlantic. Carvalho et al.(1981) determinaram teores de umidade para as variedades Bintje e Radosa $(81,08 \%$ e $81,49 \%)$ e sólidos totais $(18,92 \%$ e 18,52\%) respectivamente. Concluiram ainda que a batata Bintje foi à que reuniu melhores características para o processamento na forma de flocos, tendo o purê reconstituído dessa variedade sido superior, principalmente quanto a textura.

Com relação aos teores de amido a cultivar Elvira obteve o melhor desempenho com 16,84\%, seguida a Delta com 15,27\%, ficando em último lugar a cultivar Achat com 13,30\%. A variação entre o melhor e pior percentual de amido em 3,54\%. Freitas et al. (2006) encontrou para diversas cultivares analisadas, valores considerados baixos para amido. Destacou ainda que esta alteração na composição química da matéria seca, implica em perda da qualidade do produto final. Atribuiu ainda que condições climáticas desfavoráveis foram responsáveis pelo baixo acúmulo deste carboidrato. Braun et al. (2010) avaliando os teores de amido das cultivares Ágata, Asterix, Atlantic e Monalisa, encontrou respectivamente: $10,97 \%, 13,32 \%, 11,31 \%$ e 13,30\%, valores inferiores ao encontrado nas cultivares analisadas neste trabalho no Município de Contenda - PR.

Os valores encontrados para as cinzas variaram entre 0,40\% para a cultivar Contenda $_{2} \mathrm{e}$ 0,87\% para a Elvira. A tabela Brasileira de Composição de Alimentos, TACO-Unicamp (2006) apresentou para a batata valor médio de 0,6\% de cinzas. Quadros et al. (2009) encontraram para a cultivar Atlantic entre várias analisadas o maior teor de cinzas com 0,93\%.

As cultivares tiveram valores baixos para ácido ascórbico e acidez titulável, Contenda 1 apresentou o maior teor com 4,92 mg.100 g e quando comparado com a quantidade de vitamina C observada na cv. Atlantic, que apresentou 25,43 mg.100 $\mathrm{g}^{-1}$ (QUADROS et al., 2009). Estas diferenças podem ser atribuídas a diferenças de adubação (BREGAGNOLI, 2006) e condições de manejo incluindo diversas condições climáticas (FERNANDES et al., 2010). 


\title{
4 Conclusão
}

A partir dos resultados obtidos pode-se inferir que as cultivares Delta, Elvira e Monalisa, apresentam maior teor de sólidos totais e de amido, reunindo ótimas características físico-químicas tanto para uso doméstico quanto ao processamento industrial. Podendo ser desidratadas, enlatadas, purês e até mesmo processadas para obtenção de amido.

As cultivares Contenda ${ }_{1}$, Contenda 2 e Achat, com menores valores de sólidos e amido, é mais recomendada ao uso doméstico, tanto para saladas e batatas inteiras ao forno.

Houve predominância de tubérculos graúdos, com polpa branca à amarelada, o que atende satisfatoriamente às exigências tanto do consumo doméstico quanto industrial.

Os valores relativamente baixos para acidez titulável e ácido ascórbico para as cultivares analisadas podem ser atribuídos às condições edafoclimáticas diferenciadas e que interferem durante a produção e exercem grandes influencia na qualidade dos tubérculos.

\begin{abstract}
The potato, Solanum tuberosum L, native to the Andes region of Peru and Colombia, it was consumed for 8000 years. Tuber rich in carbohydrates, the potato has two times more protein than cassava, plus vitamins and minerals. The Brazilian consumes approximately $13 \mathrm{~kg} /$ year, while the average consumption of Europeans and Americans is five times greater. These data indicate the great potential for increasing potato consumption in Brazil. The City of Strife has been one of the largest potato producers in the state of Parana. This study evaluated the varieties Achat, Contenda, Delta, Elvira and Monalisa on the content of its main physical and chemical components: moisture, ash, total solids, starch, titratable acidity and vitamin C. The commercial classification was also performed. The varieties Delta, Elvira and Monalisa, in that order, showed the best results for total solids, a parameter of great importance for the indication of different varieties as to their household or technological. The highest content of total solids was presented by the variety Delta (20.62\%), followed varieties Elvira and Monalisa (20.10 and 19.69\%) respectively. The highest starch content was found in cultivar Elvira, 16.84\%, followed by cultivar Delta, with 15.27\%. In relation to

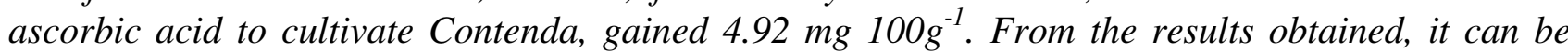
concluded the importance of the physical chemistry of different potato varieties for processing the correct indication, either domestic or industrial.
\end{abstract}

Key-words: Solanum tuberosum; varieties; composition; technological indications.

\section{Referências}

ANDREU, M. A. Industrialização e melhoramento genético da batata: desafios para um futuro próximo. Batata Show, n. 3, p. 22, dez. 2003.

AOAC. Official methods of analysis of Association official Analytica Chemists. Sidney Willians. 14 ed. VirginiaUSA. 1984. 1141p.

BOBIO, O. F.; BOBBIO, A. P. Introdução à Química de Alimentos. Campinas - SP, editora Varela. 1989.

BRASIL. Ministério da Saúde. Agência Nacional de Vigilância Sanitária. Instituto Adolfo Lutz. Métodos Físicos e Químicos para Análise de Alimentos. 4. ed. Brasília, 2005. 1018 p. 
BRAUN, H.; FONTES, P. C. R.; FINGER, F. L.; BUSATO, C.; CECON, P. R. Carboidratos e Matéria Seca de Cultivares de Batata Influenciada por Doses de Nitrogênio. Ciências Agrotécnicas, v. 34, n. 2, p. 285-293, 2010.

BREGAGNOLI, M. O. Qualidade e produtividade de batata para indústria sob diferentes adubações. $142 \mathrm{f}$. Tese. Escola Superior de Agricultura “Luis de Queiroz”, Universidade de São Paulo, Piracicaba, 2006.

BUSO, J. A. Características das Cultivares de Batatas Mais Plantadas no Brasil. In: Encontro Nacional de Produção e Abastecimento de Batata. v. 3. 1989: Contenda-PR. Anais: SOB, 1989.

CARDOSO, M. R. O. SATURNINO, H. M. Cultivares de Batata. Os cultivares e suas características. Correio Agrícola. Bayer. n. 3. 1982.

CHENG, H.; KEZIS, A. S. PEAVEY, S. R. Factors affecting consumer purchase decision for round white potatoes. American Potato Journal, n. 67, p. 719-726, 1990. http://dx.doi.org/10.1007/BF03044018

DIAS, C. A C. Batatinha. Uma cultura muito lucrativa para quem planta com cuidado. São Paulo: Ícone. 1986.

FREITAS, R. S. Técnicas Analíticas de alimentos. Curitiba: Instituto de Tecnologia do Paraná. 1979.

FERNANDES, A. M.; SORATTO, R. P.; EVANGELISTA, R. M.; NARDIN, I. Qualidade físico-química e de fritura de tubérculos de cultivares de batata na safra de inverno. Horticultura brasileira, v. 28, n. 3, 2010. http://dx.doi.org/10.1590/S0102-05362010000300010

FREITAS, S. T.; BISOGNIN, D. A.; GOMEZ, A. C. S.; SAUTER, C. K.; COSTA, L. C.; RAMPELOTTO, M. V. Qualidade para processamento de clones de batata cultivados durante a primavera e outono no Rio Grande do Sul. Ciência Rural, v. 36, n.1, p. 80-85, 2006. http://dx.doi.org/10.1590/S0103-84782006000100012

GOULD, W. A.; PLIMPTON, S. L. Quality evaluation of potato cultivars for processing. OhioAgricultural Reserch Development Center. N. 1172. 1987.

IBGE - Instituto Brasileiro de Geografia e Estatística. Levantamento Sistemático da Produção Agrícola. Disponível em: <http://www.ibge.gov.br/home/estatistica/pesquisas/pesquisa_resultados.php?indicador=1\&id_pesquisa=15>. Acesso em: 22 de maio 2012

FERNANDES, A. M.; SORATTO, R.P.; EVANGELISTA, R.M.; NARDINI, I. Qualidade físico-química e de fritura de tubérculos de cultivares de batata na safra de inverno. Horticultura Brasileira, v. 28, p. 299-304, 2010.

FILISETTI, T. M. C. C.; LOBO, A. R. Fibra alimentar e seu efeito na biodisponibilidade de minerais. In: COZZOLINO S. M. F. Biodisponibilidade de nutrientes. São Paulo: Manole, 2007. p. 175-215.

IAL-Instituto Adolfo Lutz. Métodos físico-químicos para análise de alimentos. ZENEBON O., PASCUET N. S., TIGLEA P. Método 012/IV. 1 ed. digital, p. 98-99, 2008.

KADAM, D. K.; SALUNKHE, D. K. Introduction. In: SALUNKHE, D. K.; KADAM, D. K.; JADHAV, S. J. Potato: production, processing and products. Boca Raton, Florida: USA. CRC Press, 1991.

KELKAR, M.; SHASTRI, P.; RAO, B. Y. Effect of processing on in vitro carbohydrate digestibility of cereals and legumes. Journal Food Science Technology, v. 33, n. 06, p. 4932-4937, 1996.

LESCZCZYNSKI, W. Introduction. In: LISINSKA, G.; LESCZCZYNSKI, W. Potato Science and Technology. Elsevier, London. 1989.

MARAWAHA, R. S. Nutritional composition of commonly cultivated potatos varieties. The Indian Journal of Nutrition and Dietetics. n. 25, p. 26-32. 1988.

NONAKA, M.; TIMM, H. Textural quality of cooked potatoes: II Relationship of steam cooking time to cellular strength of cultivars with similar and differing solids. American Potato Journal, n. 60, set. 1983.

PINELI, L. L. O. ; MORETTI, C. L.; ALMEIDA, G. C.; SANTOS, J. Z. ONUKI, A. C. A.; NASCIMENTO, A. B. G. Caracterização química e física de batatas 'Ágata' minimamente processadas, embaladas sob diferentes atmosferas modificadas ativas. Ciência e Tecnologia de Alimentos, v. 26, n. 1, p. 127-134, 2006. http://dx.doi.org/10.1590/S010120612006000100022 
POPP, P. A. A industrialização de batata no Brasil. In: ENCONTRO NACIONAL DE PRODUÇÃO E ABASTECIMENTO DE BATATA, 7., 1994, Araucária. Anais... Araucária: IAPAR, p.60-61, 1994.

QUADROS, D. A.; IUNG, M. C.; FERREIRA, S. M. R.; FREITAS, R.. S. Composição química de tubérculos de batata para processamento,cultivados sob diferentes doses e fontes de potássio. Ciência e Tecnologia de Alimentos, v. 29, p. 2, p. 316-323, 2009.

SALUNKHE, D. K.; KADAM, S. S.; JADHAV, S. J. Potato: production, processing and products. CRC PRESS. FLORIDA: USA 1991.

SEAB - Secretaria de Agricultura e Abastecimento do Estado do Paraná. Acompanhamento da Situação Agropecuária do Paraná. Hortaliças: Batata, out/nov 1990.

STRINGHETA, P. C. Agroindústria. Conservação da Batata através da desidratação. In: Encontro Nacional de Produção e Abastecimento de Batata. Anais: 3, Contenda-PR. 1989.

UNICAMP. Tabela Brasileira de Composição de Alimentos - TACO. 2 ed. Campinas, 2006. 113 p.

TOPUZ, A; OZDEMIR, F. Assessment of carotenoids, capsaicinoids and ascorbic acid composition of some selected pepper cultivars (Capsicum annuum L.) grown in Turkey. Journal of Food Composition and Analysis, v. 20, n. 7, p. 596-602, 2007.http://dx.doi.org/10.1016/j.jfca.2007.03.007

USP. Departamento de Alimentos e Nutrição Experimental/BRASILFOODS, Faculdade de Ciências Farmacêuticas. Tabela Brasileira de Composição de Alimentos-USP. Versão 4.1. São Paulo, 1998. Disponível em: $<$ http://www.fcf.usp.br/tabela> Acesso em: 10 Out. 2005.

WOOLFE, J.A. The potato in the human diet. In: SALUNKHE, D. K.; KADAM, S. S.; JADHAV, S. J. Potato: production, processing and products. CRC PRESS. FLORIDA: USA. 1991. p. 1-7.

Submetido em 16 set 2011, Aceito para publicação em 21 mai. 2012. 